\title{
Detecting high functioning autism spectrum disorders among neurological and medical patients in adulthood: A brief checklist to suspect the diagnosis.
}

\author{
Roberto Keller* \\ Adult Autism Center, Health Unit ASL City of Turin, Torino, Italy
}

Accepted on May 07, 2017

Autism spectrum disorders (ASDs) are a group of neurodevelopmental disabilities characterized by deficit in social communication and social interaction across contexts, restricted, repetitive patterns of behaviors, interests or activities, atypical sensoriality with symptoms present in early childhood but that could be not fully manifest until social demands exceed limited capacities (DSM 5). The dimensional clinical continuum ranges from minimal autistic traits to full-blown autism and from severe mental retardation to high functioning autism (HFA) with normal or high IQ. Developmental abnormalities later leading to autism begin in most cases prenatally and widely disrupt brain network connectivity [1,2]. ASD is strongly biased towards males, with ratios of 4:1 (Male-Female) for classic autism as high as 11:1 in Asperger disorder (the form of ASD most near to neurotypical people). ASD almost always shows stability in clinical diagnosis lifetime. In DSM 5 (APA) Asperger disorder is considered strictly linked to HFA and included in the spectrum as ASD Level 1. Even if symptoms typically are apparent in childhood, in Asperger disorder the clinical presentation could be not diagnosed until adulthood [3]. During childhood, and adolescence, the high intellectual functioning could compensate the impairment in social cognition and the patient could not be referred to a physician, but many people with HFA are significantly disadvantaged regarding education, employment, social relationships, physical and mental health, and especially quality of life [4].

In adulthood, the clinical presentation of HFA could be modified from life experience, social impairment could improve and the diagnosis could be uneasy. ASD patients referred to neuropsychiatrist could be misdiagnosed as others neuropsychiatric disorders even because a neuropsychiatric comorbidity could also occurs as depressive disorder or anxiety disorder (as reaction to being bullied) or bipolar disorder or psychosis (as paranoid reaction to lack of social understanding) or drug abuse (as alcoholism for self-treating anxiety) or anorexia nervosa (as restricted interest on food and starvation) or OCD or tic disorder (instead of stereotypy) [5, 6].

In our clinical center, specialized in autism spectrum disorder in adulthood, we observed adults with HFA without diagnosis until our clinical observation. Before ASD diagnosis they were treated for another uncorrect o partially correct diagnosis: or a complete misdiagnosis, etc. Obsessive compulsive psychosis instead of HFA, or a uncomplete misdiagnosis, as depressive disorder really present but forgetting the HFA and the social cognition deficit causing depression.

The most frequent misdiagnosis observed in our centre are: social phobia, obsessive compulsive disorder, defiant personality disorder, Schizotypal personality disorder, obsessive personality disorder, schizophrenia with negative symptoms and tic disorder.

In 95 adult new outpatients referring to our centre in one year, 20 has no diagnosis or a other psychiatric diagnosis (Table 1).

We suggest a rapid checklist that could be useful for clinicians to suspect HF-ASD in adulthood (Table 2). All our patient scored off 10 point at the checklist. A specific evaluation should be carried on, using validate test to confirm clinical diagnosis. The cognitive profile should be detected at least with Wechsler test and if possible with complete neuropsychological evaluation.

Table 1. In 95 adult new out-patient referring to our centre in one year, 20 has no diagnosis or a other psychiatric diagnosis

\begin{tabular}{|c|c|c|c|}
\hline $\begin{array}{l}\text { Age of first ASD } \\
\text { diagnosis }\end{array}$ & Gender & Before diagnosed as & Checklist score \\
\hline 25 & $M$ & social phobia & 10 \\
\hline 49 & $\mathrm{~F}$ & social phobia & 11 \\
\hline 33 & $\mathrm{M}$ & no diagnosis & 11 \\
\hline 19 & M & no diagnosis & 11 \\
\hline 19 & $\mathrm{M}$ & social phobia & 11 \\
\hline 22 & $M$ & social phobia & 11 \\
\hline 31 & $M$ & OCD & 10 \\
\hline 32 & $M$ & social phobia & 10 \\
\hline 19 & $M$ & OCD and tic disorder & 11 \\
\hline 50 & $M$ & no diagnosis & 11 \\
\hline 64 & $M$ & schizophrenia paranoid & 11 \\
\hline 50 & M & schizophrenia negative & 10 \\
\hline 24 & M & $\begin{array}{l}\text { schizotypal personal } \\
\text { isord }\end{array}$ & 12 \\
\hline 41 & M & no diagnosis & 11 \\
\hline 43 & $M$ & OCD & 11 \\
\hline 29 & $M$ & no diagnosis & 11 \\
\hline 44 & $\mathrm{M}$ & schizophrenia paranoid & 10 \\
\hline 32 & M & OCD & 10 \\
\hline 24 & M & no diagnosis & 10 \\
\hline 19 & M & $\begin{array}{l}\text { OCD and defiant } \\
\text { personal dis }\end{array}$ & 11 \\
\hline
\end{tabular}


Citation: Keller R. Detecting high functioning autism spectrum disorders among neurological and medical patients in adulthood: A brief checklist to suspect the diagnosis. J Neurol Neurorehabil Res. 2017;2(1):34-35.

Table 2. Short checklist to suspect HF-ASD in adulthood.

1. Before diagnosed as social phobia, obsessive compulsive disorder, tic disorder, defiant personality disorder, schizothypal personality disorder, obsessive personality disorder, schizophrenia especially with negative or paranoid symptoms.

2. At the neuropsychiatric examination, the clinical presentation could shows: no direct eye contact, logorrhea but with restricted to one topic, no reciprocity in the dialogue, stereotyped movements, no adequate social interaction compared to intellectual and cultural level.

3. Normal or high IQ at Wechsler

4. Familiarity for ASD or schizophrenic spectrum disorder or obsessive compulsive spectrum disorder or tic

5. Described by teachers and/or relatives as socially retired in the first school approach (from 3 to 8 years old)

6. Deficit in symbolic playing (as faking or acting like or imitating job parents) in childhood

7. Difficulties in playing with other children out from family as in the public park, especially social role games or preferring playing alone, usually with repetitive games as series, back to back or rotation.

8. Restricted or unusual interest in childhood or stereotyped movements or verbal repetitive expressions in childhood

9. Goffy in childhood and not prone to handiness exercise

10. Bullied in childhood or adolescence or mobbing.

11. Difficulties in social relationship, especially in break time at school or friends party in childhood or adolescence, also present in adulthood.

12. Unusual expressive modalities as in loudness, or few mimic variety since childhood.

13. Difficulties in understanding not concrete language as metaphor, proverb also in adulthood.

\section{References}

1. Cauda F, Costa T, Palermo S, et al. Concordance of white matter and gray matter abnormalities in autism spectrum disorders: A voxel-based meta-analysis study. Hum Brain Mapp 2013.

2. American Pychiatric Association, APA. Diagnostic and statistical manual of mental disorders DSM-fifth Edition, 2013.

3. Arora M, Praharaj SK, Sarkhel S, et al. Asperger disorder in adults. South Med J 2011; Apr 104(4):264-8.
4. Howlin P, Moss P. Adults with autism spectrum disorders. Can J Psychiatry 2012; May 57(5):275-83

5. Keller R, Piedimonte A, Bianco F, et al. Diagnostic characteristics of psychosis and autism spectrum disorder in adolescence and Adulthood. A Case Series. Autism Open Access. 2015;6:159.

6. Luciano CC, Keller R, Politi P, et al. Misdiagnosis of high function autism spectrum disorders in adults: An Italian case series. Autism. 2014;4:131.

\section{*Correspondence to:}

Adult autism center Health Unit ASL City of Turin Torino

Italy

Tel: 393480369283

E-mail: rokel2003@libero.it 